\title{
PHYSIOLOGICAL BASIS OF SALINITY TOLERANCE IN FOXTAIL MILLET
}

\author{
S. Akter ${ }^{1 *}$, M.A. Mannan ${ }^{1}$, M.A.A. Mamun' ${ }^{1}$ and M.S. Islam ${ }^{2}$ \\ ${ }^{1}$ Department of Agronomy, ${ }^{2}$ Department of Soil Science \\ Bangabandhu Sheikh Mujibur Rahman Agricultural University, Gazipur-1706, Bangladesh \\ *Corresponding E-mail: mannanbsmrau@yahoo.com
}

(Received: 17 December 2019, Accepted: 04 January 2020)

Keywords: Physiology, salinity, tolerance, foxtail millet

\begin{abstract}
A pot experiment was conducted to study the effects of salt stress on physiological parameters associated to salinity tolerance in foxtail millet plant in the Department of Agronomy, Bangabandhu Sheikh Mujibur Rahman Agricultural University, Gazipur, Bangladesh during March to May, 2018. Four foxtail millet genotypes namely i) BD-881 ii) BD-897 iii) BD-878 and iv) BARI kaon-1 were grown and each pot was irrigated using three levels of saline water viz. control (tap water), $60 \mathrm{mM}$ saline water and $120 \mathrm{mM}$ saline water. Results indicated that genotypic variability was profound in salinity tolerance in foxtail millet. The leaves of BD-878 maintained higher water content, higher accumulation of proline, and lower accumulation of malondialdehyde (MDA) as well as less reduction of chlorophyll compared to other genotypes studied. BD-878 also showed relatively higher salinity stress tolerance, while BD-897 was susceptible in relation to yield. Higher salinity tolerance in BD-878 was associated with higher relative leaf water and chlorophylls with accumulation of higher amount of proline and lower accumulation of malondialdehyde content.
\end{abstract}

\section{Introduction}

The changes foreseen under climate change scenarios are the changes in the pattern of rainfall, rather than the quantum, leading to long spells of drought and spells of water-logging of the soils as well as salinity. Foxtail millet is considered to be an ideal crop for the changing climate due to its short duration, high photosynthetic efficiency, nutritional richness and low incidence of pest and diseases (Vetriventhan et al., 2012) and has been reported to have comparable tolerant level to drought (Doust et al., 2009) and salinity (Kafi et al., 2009). Foxtail millet can be a potential crop for salt affected soils due to its high level of tolerance to salinity (Maas, 1985) and the salt 'escape' potential due to its short growing duration.

Salt stress induces several morphological, physiological, biochemical and molecular responses in several crop plants, which would help them to adapt to such limiting environmental conditions (Arora et al., 2002). It inhibits the photosynthesis of plants, causes changes of chlorophyll contents and damages the photosynthetic apparatus (Escuredo et al., 1998). Osmotic adjustment is the decrease of osmotic potential by the active accumulation of organic as well as inorganic solutes within the cells. High concentrations of inorganic ions become detrimental to cellular metabolism and must be sequestered in the vacuole. In order to keep osmotic balance, specific types of organic molecules (such as soluble sugars, betains, proline etc) are accumulated in the cytoplasm. Those compounds protect plants 
against stresses by cellular adjustment through the protection of membranes integrity and enzymes stability (Farooq et al., 2009). These compounds are termed as compatible solutes, because they can be accumulated in high concentrations without impairing normal physiological function. So, aiming of this research work was to analyze the changes of morpho-physiological parameters that are associated with the salinity tolerance in foxtail millet as well as to study the effects of salinity on dry matter accumulation and yield of foxtail millet.

\section{Materials and Methods}

The experiment was conducted at the Department of Agronomy, Bangabandhu Sheikh Mujibur Rahman Agricultural University, Gazipur, Bangladesh. The experimental site is the center of Madhupur tract (AEZ 28) $\left(24.09^{\circ} \mathrm{N}\right.$ latitude and $90.26^{\circ} \mathrm{E}$ longitudes) at $8.4 \mathrm{~m}$ above the mean sea level. The experiment was carried out employing 4 foxtail millet genotypes namely i) BD-881 ii) BD-897 iii) BD-878 and iv) BARI kaon-1. The plants were grown in plastic pots of $24 \mathrm{~cm}$ diameter $\times 30 \mathrm{~cm}$ height in size filled with soil inside plastichouse under natural light during March to May, 2018. The soil used in the pot was clay loam in texture and poor fertility status. The $\mathrm{pH}$ of the soil was 7.1 , organic carbon- $0.60 \%$, total $\mathrm{N}-0.05 \%$, available P$0.08 \mathrm{mg} / 100 \mathrm{~g}$ dry soil, exchangeable $\mathrm{K}-0.33 \mathrm{cmol}_{\mathrm{c}} \mathrm{kg}^{-1}$ dry soil and CEC- $14.58 \mathrm{cmol}_{\mathrm{c}} \mathrm{kg}^{-1} \mathrm{dry}$ soil. Compost ( $1 / 4$ th of the soil volume) and $0.27-0.28-0.20 \mathrm{~g}$ of urea, triple super phosphate and muriate of potash per pot for supplying $\mathrm{N}, \mathrm{P}_{2} \mathrm{O}_{5}$ and $\mathrm{K}_{2} \mathrm{O}$, respectively were incorporated uniformly into the soil. The compost was made mostly from cow dung which contained $0.8 \%$ $\mathrm{N}, 0.6 \% \mathrm{P}_{2} \mathrm{O}_{5}$ and $1.0 \% \mathrm{~K}_{2} \mathrm{O}$ on dry weight basis. Ten to fifteen bold seeds were sown in each plastic pot containing about $12 \mathrm{~kg}$ air dried soil. After seedling establishment, six uniform and healthy plants were allowed to grow in each pot. Three levels of salt solution viz. i) Tap water (control) ii) $60 \mathrm{mM}$ salinity and $120 \mathrm{mM}$ salinity were applied from 14 days after sowing to maturity. Normal management practices were applied for all the treatments. The experiment was conducted with completely randomized design (CRD) with three replications. The plant height and total dry weight (stem +leaf) were measured at 20 and 40 days after salt imposition (DASI). Leaf water content, proline, melondialdehyde (MDA) content and chlorophyll content were measured at flowering stage. The leaf water content (RWC) was measured using the formula: $[(F W-D W) /(T W-D W)] \times 100$ where, $T W=$ Turgid weight of the leaf, $F W=$ Fresh weight of the leaf, DW = Dry weight of the leaf. Proline, Melondialdehyde (MDA) content and chlorophyll content was measured according to Bates et al. (1973), Health \& Packer (1968) and Witham et al. (1986), respectively. At maturity two plants were collected from each pot, and tiller number / plant, panicle number / plant, panicle weight / plant and seed yield / plant were recorded. Data of salinity stress $(60 \mathrm{mM}$ and $120 \mathrm{mM})$ were compared with those in control (non saline water) treatment in order to understand the relative growth reduction of the individual plant part. The recorded data on various parameters were statistically analyzed by "CropStat". The treatment means were compared by Least Significance Difference (LSD) test at $5 \%$ level of significance (Gomez \& Gomez, 1984).

\section{Results and Discussion}

\section{Plant height}

The effect of salt stress on plant height was statistically significant at 20 and 40 days after salt imposition (Table 1). At 20 days, the plant height under control condition was the highest in BD-897, while the lowest was in BARI Kaon-1. At $60 \mathrm{mM}$ saline condition the highest plant height was recorded in BD-897 and the lowest was in BARI-kaon-1. Relative (per cent of 
control) plant height of the genotypes ranged from $91.87 \%$ to $96.44 \%$. Highest relative plant height was obtained from genotype BARI Kaon-1 (96.44\%), followed by BD-878 (96.04\%), and BD-897 (91.94\%) and it was lowest in BD-881 (91.87\%). At $120 \mathrm{mM}$ saline condition the highest plant height was recorded with BD-897 and the lowest was in BARI-Kaon-1. Relative (per cent of control) plant height of the genotypes ranged from $84.88 \%$ to $87.09 \%$. Highest relative plant height was obtained from genotype BD-878 (87.09\%), followed by BARI-Kaon-1 $(86.67 \%)$ and BD-881 (84.98\%) and it was lowest in BD-897 (84.88\%). Plant height reduction due to salinity was lower in BD-878 (12.91\%) while that was higher in BD897 (15.12\%). After 40 days, the highest plant height was recorded in BD-897 and the lowest was demonstrated from BARI Kaon-1 under control condition. At $60 \mathrm{mM}$ saline condition the highest plant height was recorded with BD-878 and the lowest was in BARI Kaon-1. Relative (per cent of control) plant height of the genotypes ranged from $85.41 \%$ to $91.10 \%$. Highest relative plant height was obtained from genotype BD-878 (91.10\%), followed by BD-897 (86.90\%) and BD-881 $(86.71 \%)$ and it was lowest in BARI Kaon-1 (85.51\%). At $120 \mathrm{mM}$ saline condition the highest plant height was recorded with BD-878 and the lowest was in BARI kaon-1. Relative (per cent of control) plant height of the genotypes ranged from $70.12 \%$ to $75.95 \%$. Highest relative plant height was obtained from genotype BD-878 $(75.95 \%)$, followed by BD-881 $(73.08 \%)$ and BARI-Kaon-1 (72.22\%) and it was lowest in BD-897 (70.12\%). Plant height reduction due to salinity was lower in BD- 878 (24.05\%), while that was higher in BD-897 (29.88\%). Therefore, BD-878 showed relatively higher salinity tolerance in relation to plant height than other genotypes studied. The lower height in the plants under salinity occurred, probably due the ABA action, in which it is produced in the cells under water stress condition and this way inhibit the cell division and / or DNA synthesis. Similar results on the height reduction in plant under stress were described by Lacerda et al. (2003) working with genotypes of Sorghum bicolor under salt stress.

Table 1. Plant height $(\mathrm{cm})$ of foxtail millet genotypes as affected by salinity at different days after salt imposition (DASI)

\begin{tabular}{|c|c|c|c|c|c|c|}
\hline \multirow{2}{*}{$\begin{array}{c}\text { Genotype } \\
\text { s }\end{array}$} & \multicolumn{3}{|c|}{20 DASI } & \multicolumn{3}{|c|}{40 DASI } \\
\hline & Control & $\begin{array}{l}60 \mathrm{mM} \\
\text { salinity }\end{array}$ & $\begin{array}{l}120 \mathrm{mM} \\
\text { salinity }\end{array}$ & Control & $\begin{array}{l}60 \mathrm{mM} \\
\text { salinity }\end{array}$ & $\begin{array}{l}120 \mathrm{mM} \\
\text { salinity }\end{array}$ \\
\hline BD- 881 & $135.33 \pm 78.13^{*}$ & $\begin{array}{c}124.32 \pm 71.78 \\
(91.87)\end{array}$ & $\begin{array}{c}115.00 \pm 66.40 \\
(84.98)\end{array}$ & $195.6 \pm 8.19$ & $\begin{array}{c}169.67 \pm 4.67 \\
(86.71)\end{array}$ & $\begin{array}{c}143 \pm 4.93 \\
(73.08)\end{array}$ \\
\hline BD- 897 & $136.67 \pm 78.90$ & $\begin{array}{c}125.65 \pm 72.55 \\
(91.94)\end{array}$ & $\begin{array}{c}116.00 \pm 66.97 \\
(84.88)\end{array}$ & $208.67 \pm 2.72$ & $\begin{array}{c}181.33 \pm 3.52 \\
(86.90)\end{array}$ & $\begin{array}{c}146.33 \pm 2.8 \\
(70.12)\end{array}$ \\
\hline BD- 878 & $126.33 \pm 72.94$ & $\begin{array}{c}121.30 \pm 70.05 \\
(96.04)\end{array}$ & $\begin{array}{c}105.67 \pm 61.01 \\
(87.09)\end{array}$ & $202.33 \pm 2.84$ & $\begin{array}{c}184.33 \pm 4.48 \\
(91.10)\end{array}$ & $\begin{array}{c}153.67 \pm 2.72 \\
(75.95)\end{array}$ \\
\hline $\begin{array}{l}\text { BARI } \\
\text { kaon-1 }\end{array}$ & $75.00 \pm 43.30$ & $\begin{array}{c}72.33 \pm 41.76 \\
(96.44)\end{array}$ & $\begin{array}{c}65 \pm 37.53 \\
(86.67)\end{array}$ & $96 \pm 2.08$ & $\begin{array}{l}82 \pm 2.89 \\
(85.41)\end{array}$ & $\begin{array}{c}69.33 \pm 3.18 \\
(72.22)\end{array}$ \\
\hline $\operatorname{LSD}_{(0.05)}$ & & 1.10 & & & 2.05 & \\
\hline CV (\%) & & 22.86 & & & 31.12 & \\
\hline
\end{tabular}

* Indicate SE value, values in parenthesis indicate per cent of control.

Studies carried out by Wang (2005) revealed that the ABA induce the gene expression that codify the inhibited protein of the cyclin-dependent activity (ICKI), coinciding with the results found by Jakoby et al. (2006) on extreme important of this metabolic in cell division process and consequently development and growth of plant. 
The effect of salt stress on total dry weight (leaf + stem) was statistically significant at 20 and 40 days after salt imposition (Table 2). At 20 days, the total dry weight under control condition was the highest in BD-878, while the lowest was in BARI Kaon-1. At $60 \mathrm{mM}$ saline condition the highest total dry weight was recorded with BD-878 and the lowest was in BARI-kaon-1. Relative (per cent of control) total dry weight of the genotypes ranged from $70.73 \%$ to $82.88 \%$. Highest relative total dry weight was obtained from genotype BD-878 (82.88\%), followed by BD-881 (79.70\%), and BD-897 (73.66\%) and it was lowest in BARI Kaon-1 (70.73\%). At $120 \mathrm{mM}$ saline condition the highest total dry weight was recorded with BD-897 and the lowest was in BARI Kaon-1. Relative (per cent of control) total dry weight of the genotypes ranged from $53.60 \%$ to $73.90 \%$. Highest relative total dry weight was obtained from genotype BD-878 (73.90\%), followed by BARI-Kaon-1 65.70\%) and BD-897 (65.34\%) and it was lowest in BD-881 (53.60\%). Total dry weight reduction due to salinity was lower in BD-878 (73.90\%) while that was higher in BD-(881 53.60\%). After 40 days, the highest total dry weight was recorded in BD-881 and the lowest was demonstrated from BARI Kaon-1 under control condition. At $60 \mathrm{mM}$ saline condition the highest total dry weight was recorded with BD-878 and the lowest was in BARI Kaon-1. Relative (per cent of control) total dry weight of the genotypes ranged from $(70.44 \%$ to $86.92 \%)$. Highest relative total dry weight was obtained from genotype BD-878 (86.92\%), followed by BD-881 (78.16\%) and BD-897 $(72.72 \%)$ and it was lowest in BARI Kaon-1 (70.44\%).

Table 2. Total dry weight (g) of Foxtail millet genotypes as affected by salinity at different days after salt imposition (DASI)

\begin{tabular}{lcccccc}
\hline Genotypes & \multicolumn{3}{c}{$20 \mathrm{DASI}$} & \multicolumn{3}{c}{$40 \mathrm{DASI}$} \\
\cline { 2 - 6 } & Control & $60 \mathrm{mM}$ & $120 \mathrm{mM}$ & Control & $60 \mathrm{mM}$ & $120 \mathrm{mM}$ \\
& & salinity & salinity & & salinity & salinity \\
\hline BD- 881 & $11.43 \pm 6.60^{*}$ & $9.11 \pm 5.26$ & $6.13 \pm 3.54$ & $47.01 \pm 8.71$ & $36.74 \pm 3.60$ & $29.89 \pm 2.58$ \\
& $(79.70)$ & $(53.60)$ & & $(78.16)$ & $(63.58)$ \\
BD- 897 & $11.59 \pm 6.69$ & $8.54 \pm 4.93$ & $7.57 \pm 4.37$ & $45.31 \pm 3.15$ & $32.97 \pm 4.12$ & $24.5 \pm 2.30$ \\
& & $(73.66)$ & $(65.34)$ & & $(72.72)$ & $(54.06)$ \\
BD- 878 & $12.19 \pm 7.04$ & $10.10 \pm 5.83$ & $7.47 \pm 4.31$ & $45.21 \pm 8.08$ & $39.30 \pm 1.87$ & $34.93 \pm 1.51$ \\
& & $(82.88)$ & $(73.90)$ & & $(86.92)$ & $(77.26)$ \\
BARI kaon-1 & $8.75 \pm 5.05$ & $6.19 \pm 3.57$ & $5.75 \pm 3.32$ & $27.17 \pm 0.95$ & $19.14 \pm 1.50$ & $15.78 \pm 1.60$ \\
& & $(70.73)$ & $(65.70)$ & & $(70.44)$ & $(58.06)$ \\
\hline LSD & 0.15 & & & 0.10 \\
\hline CV $(\%)$
\end{tabular}

* Indicate SE value, values in parenthesis indicate per cent of control.

At $120 \mathrm{mM}$ saline condition the highest total dry weight was recorded with BD-878 and the lowest was in BARI-Kaon-1. Relative (per cent of control) total dry weight of the genotypes ranged from $54.06 \%$ to $77.26 \%$. Highest relative total dry weight was obtained from genotype BD-878 $(77.26 \%)$, followed by BD-881 (63.58\%) and BARI-Kaon-1 (58.06\%) and it was lowest in BD-897 (54.06\%). Total dry weight reduction due to salinity was lower in BD-897 (45.94\%) while that was higher in BD-878 $(22.74 \%)$. Stress condition caused significant decrease in plant growth. These results were in harmony with Abass and Mohamed (2011) who reported that the plant growth parameters of common bean (shoot and root length, fresh and dry weights of shoots and roots) decreased significantly with increasing drought stress as compared with control plants. Such decline in shoot and root growth in response to stress might be due to either decrease in cell elongation, cell turgor, cell volume and eventually cell growth (Banon et al., 2006), and/or due to blocking up of xylem and phloem vessels thus hindering any translocation through (Lavisolo and Schuber, 1998). 


\section{Leaf water content}

The effect of salt stress on leaf water was statistically significant (Figure 1). At $60 \mathrm{mM}$ saline condition relative (per cent of control) leaf water of the genotypes ranged from $69 \%$ to $87 \%$. Highest relative leaf water was obtained from genotype BD-878 (87\%), followed by BARI Kaon-1 (79\%), and BD-881 (78\%) and it was lowest in BD-897 (69\%). At $120 \mathrm{mM}$ saline condition relative (per cent of control) leaf water content of the genotypes ranged from $63 \%$ to $84 \%$. Highest relative leaf water was obtained from genotype BD-878 $(84 \%)$, followed by BARI-Kaon-1 (75\%) and BD-881 (68\%) and it was lowest in BD-897 (63\%). The reduction in leaf RWC (\%) was provoked by the water deficiency in soil, in which the water stress due to salinity effect simulated artificially in this experiment cause as direct consequence changes in LRWC, because during the transpiration process and photosynthesis occur water loss through of the stomata and the assimilation / reposition rate is strongly affected, occurred probably decrease of the conductance stomatal for reduce the water loss to the atmosphere (Verslues et al., 2006). Velu and Palanisami (2001) also reported that water stress significantly reduced relative water content of the plant.

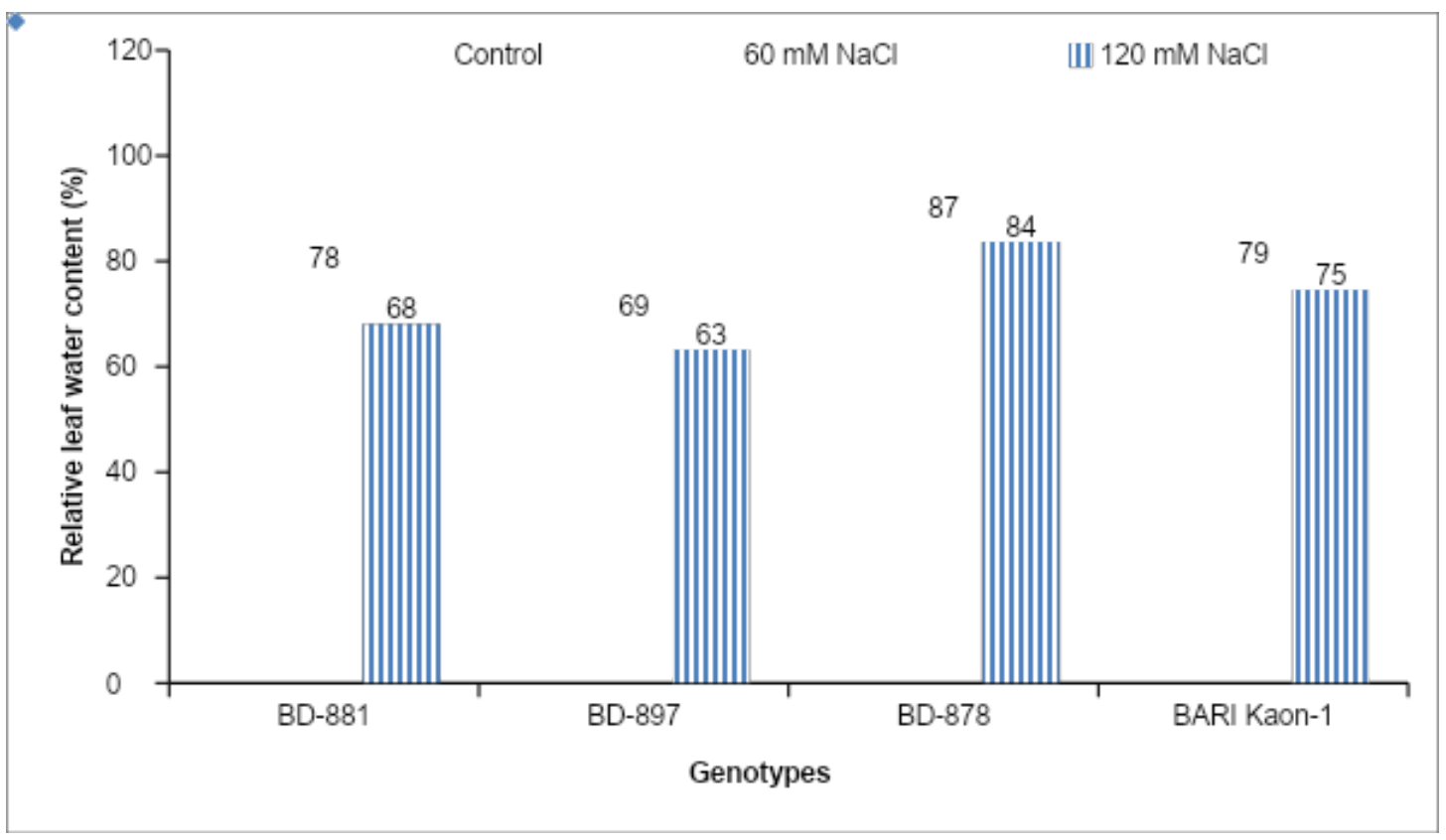

Fig. 1. Relative leaf water content of four Foxtail millet genotypes as affected by salinity.

\section{Chlorophyll a}

The effect of salt stress on chlorophyll content was statistically significant (Figure 2). At 60 $\mathrm{mM}$ saline condition relative (per cent of control) leaf water of the genotypes ranged from $69 \%$ to $85 \%$. Highest relative chlorophyll a content was obtained from genotype BARI Kaon-1 (85\%), followed by BD-878 (82\%) and BD-881 (75\%) and it was lowest in BD-897 (69\%). At $120 \mathrm{mM}$ saline condition relative (per cent of control) chlorophyll a content of the genotypes ranged from $60 \%$ to $75 \%$. Highest relative leaf water was obtained from genotype BD-878 $(75 \%)$, followed by BARI-Kaon-1 (70\%) and BD-897 (61\%).and it was lowest in BD-881 $(60 \%)$. 


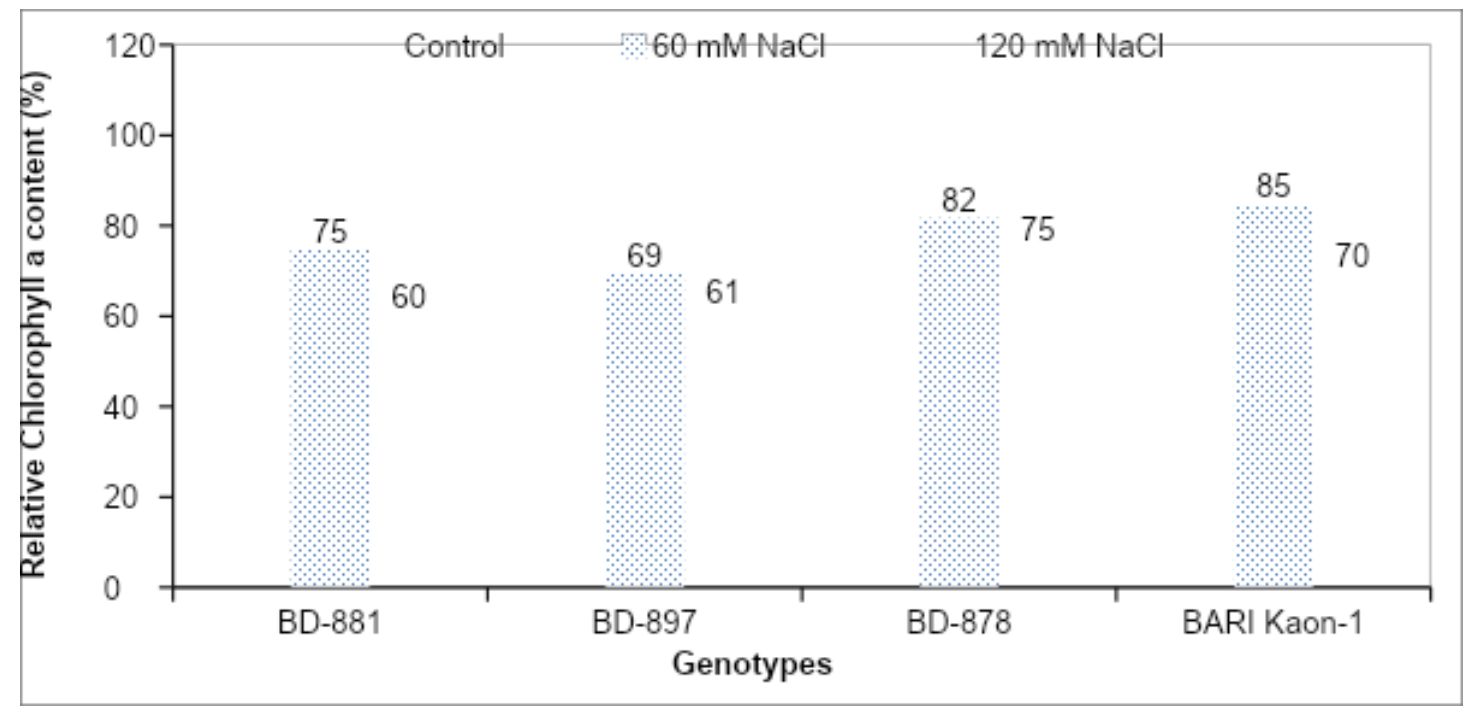

Fig. 2. Relative Chlorophyll a content of four Foxtail millet genotypes as affected by salinity.

\section{Chlorophyll b}

The effect of salt stress on chlorophyll b was statistically significant (Figure 3). At $60 \mathrm{mM}$ saline condition relative (per cent of control) chlorophyll b content of the genotypes ranged from $47 \%$ to $78 \%$. Highest relative leaf water was obtained from genotype BD-878 (78\%), followed by BD-881 (76\%), BD-897 (60\%) and it was lowest in BARI Kaon-1 (47\%). At 120 $\mathrm{mM}$ saline condition relative (per cent of control) chlorophyll b content of the genotypes ranged from $24 \%$ to $63 \%$. Highest relative leaf water was obtained from genotype BD-878 (63\%), followed by BD-881 (57\%), BD-897 (57\%) and it was lowest in BARI-Kaon-1 (24\%).

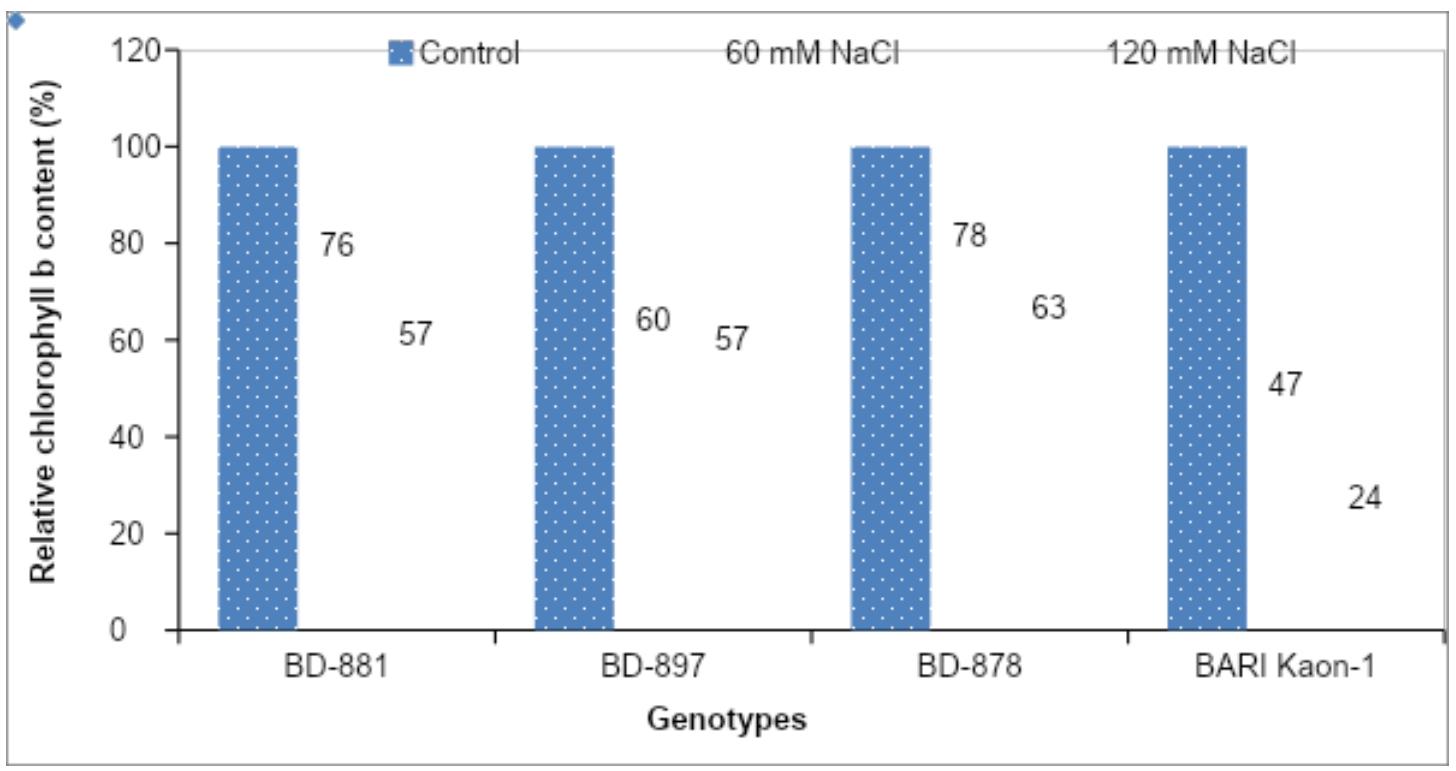

Fig. 3. Relative Chlorophyll b content of four Foxtail millet genotypes as affected by salinity. 


\section{Total chlorophyll content}

The effect of salt stress on total chlorophyll content was statistically significant (Figure 4). At $60 \mathrm{mM}$ saline condition relative (per cent of control) total chlorophyll content of the genotypes ranged from $61 \%$ to $80 \%$. Highest relative total chlorophyll was obtained from genotype BD-878 (80\%), followed by BD-881 (75\%) and BD-881 (75\%) and it was lowest in BD-897 (66\%) BARI Kaon-1 (61\%), At $120 \mathrm{mM}$ saline condition relative (per cent of control) leaf chlorophyll content of the genotypes ranged from $41 \%$ to $70 \%$. Highest relative leaf total chlorophyll was obtained from genotype BD-878 $(70 \%)$, followed by BD-897 $(60 \%)$ and BD-881 (59\%) and it was lowest in BARI-Kaon-1 (41\%). The reduction of the total chlorophyll due to salt stress was lower in BD-878 (30\%), while that was higher in BARI Kaon-1 (59\%). Abass and Mohamed (2011) who reported that photosynthetic pigments contents in leaves of common bean plants were highly significantly decreased with increasing the level of drought stress. Sairam et al. (2002) showed higher decrease in pigment contents of wheat genotypes under salinity at the three stages. The observed decrease of Chlorophyll content in the plants grown under saline conditions may be attributed to both of the increased degradation and the inhibited synthesis of that pigment (Garsia et al., 2002). The reduction in chlorophyll content under stress has been considered a typical symptom of oxidative stress and may be the result of pigment photo-oxidation and chlorophyll degradation. The decrease in the photosynthetic activity under stress may be due to stomatal or non-stomatal mechanisms. Stomata closure is one of the first responses to drought stress which result in declined rate of photosynthesis. The drought induced reduction in the chlorophyll content could be attributed to loss of chloroplast membranes, excessive swelling, and distortion of the lamellae vesiculation and the appearance of lipid droplets. It was also reported that this pigment was sensitive to increasing environmental stress (Terzi et al., 2010). The decrease in total chlorophyll content may have resulted from a decrease in leaf water status in the soybean.

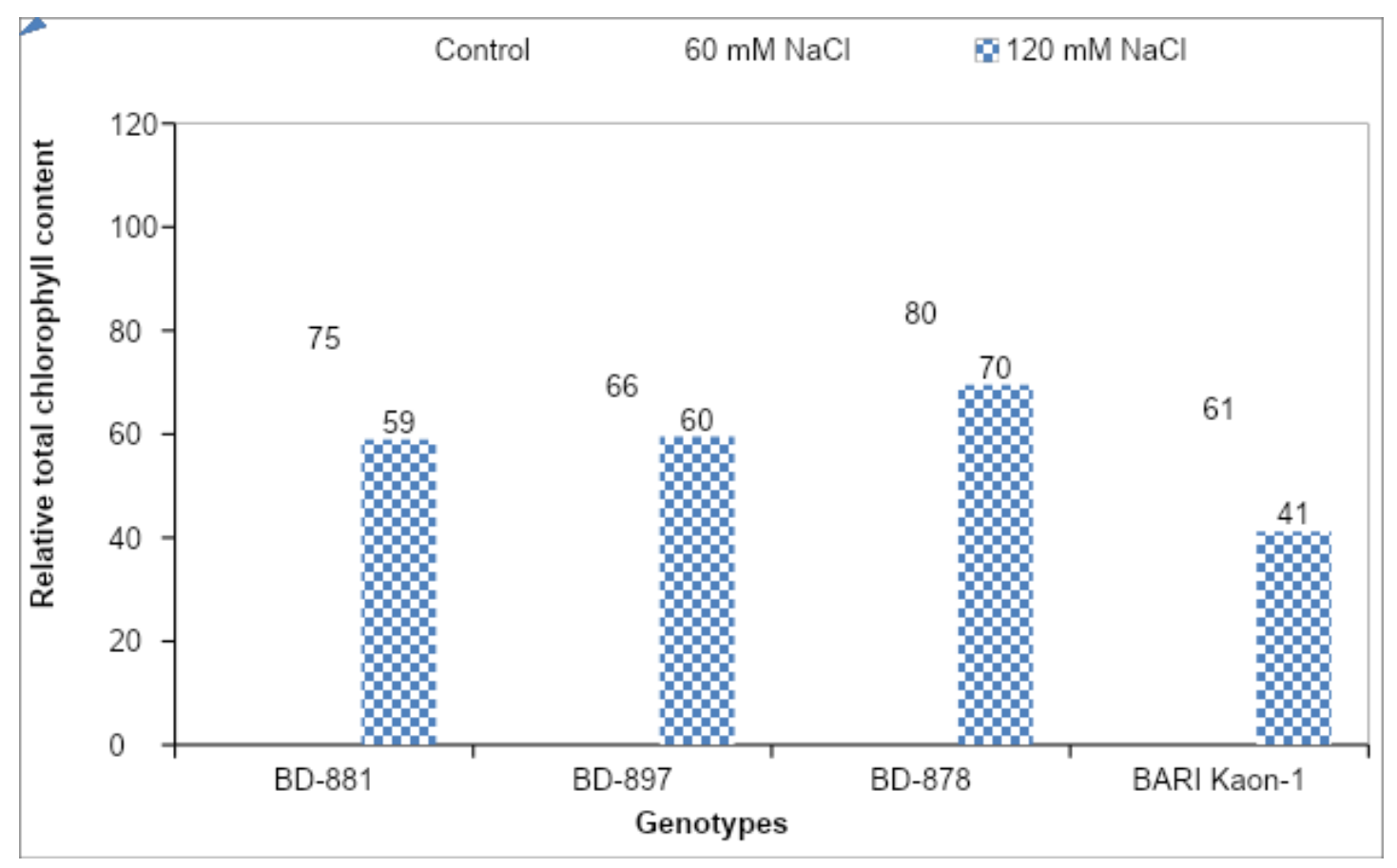


Fig. 4. Relative total Chlorophyll content of four Foxtail millet genotypes as affected by salinity.

\section{Proline content}

The effect of salt stress on proline content was statistically significant (Figure 5). At $60 \mathrm{mM}$ saline condition relative (per cent of control) proline content of the genotypes ranged from $124 \%$ to $157 \%$. Highest relative proline content was obtained from genotype BD-878 (157\%), followed by BARI Kaon-1 (135\%), and BD-897 (129\%) and it was lowest in BD-881 (124\%). At $120 \mathrm{mM}$ saline condition relative (per cent of control) proline content of the genotypes ranged from $157 \%$ to $179 \%$. Highest relative proline content was obtained from genotype BD-878 (179\%), followed by BARI-Kaon-1 (164\%) and BD-897 (161\%) and it was lowest in BD-881 (157\%). The proline accumulation is a metabolic response characteristic of plants under abiotic stresses, it being showed the increase in this experiment because the free proline work as osmotic adjustor that objective reduce the negative effects provoked in the plants under adverse conditions Zhu (2002).

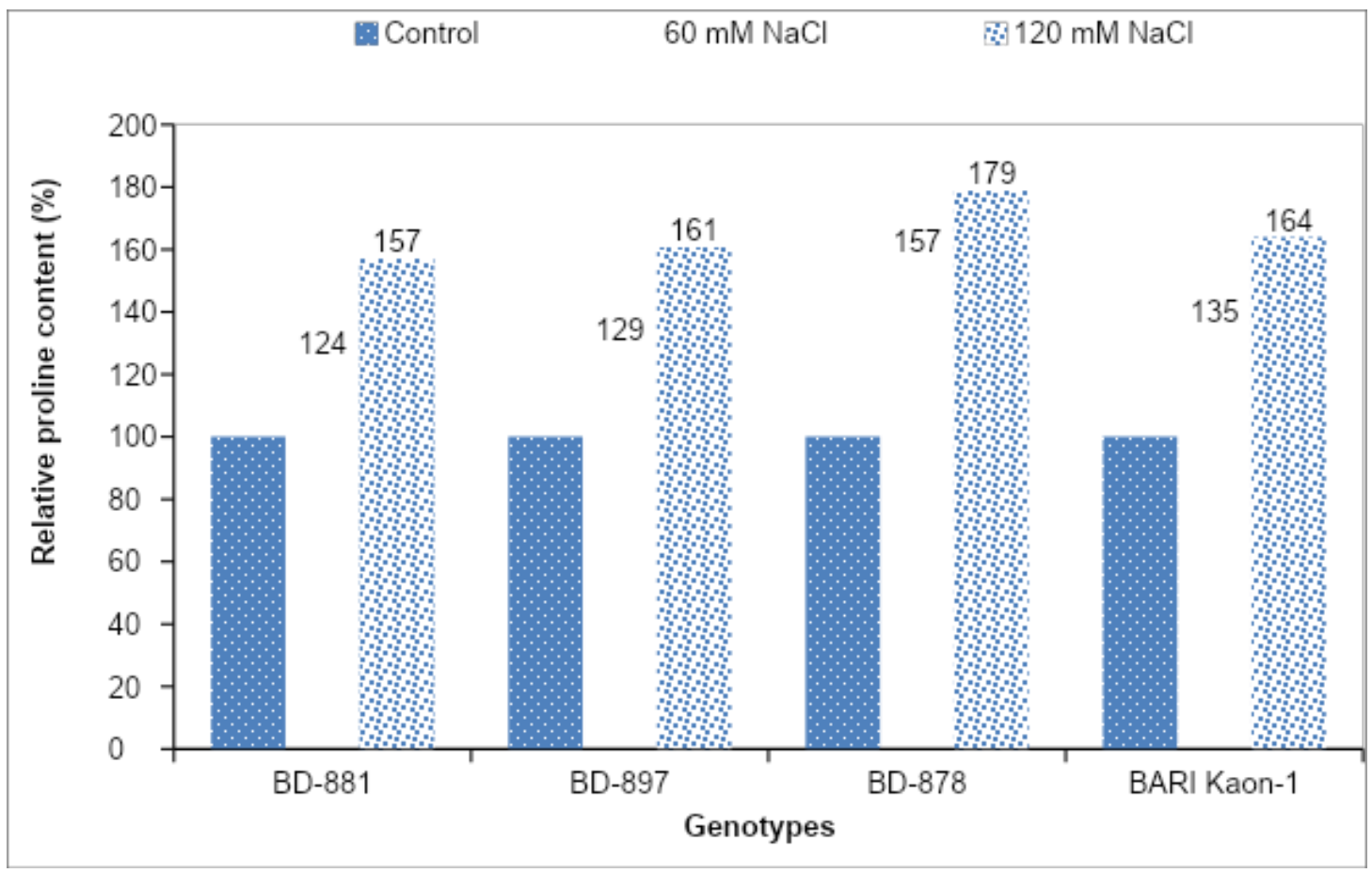

Fig. 5. Relative proline content of four Foxtail millet genotypes as affected by salinity

Proline is known to play as an osmoprotectant in plants subjected to osmotic stresses resulted from drought and soil salinity. A positive correlation between proline accumulation and osmoticstress tolerance has been reported by Muthulakshmi et al. (2013), Abraham et al. (2003), Abdelhamid et al. (2013), Khattab (2007), Amirjani (2010), Sadak and Dawood (2014) and Taie et al. (2013). Remarkable increase in proline content under stress conditions could be due to changes in proline metabolism profile under salinity stress, with an increased expression of proline synthetic enzymes and breakdown of proline-rich protein (Tewari and Singh, 1991). According to Kaouther et al. (2012) investigations with Chili pepper (Capsicum frutescens ) obtained results showing significant increase in proline in all cultivars with the 
increase of salt concentration in irrigation water. The accumulation of osmolyte compounds is often proposed as a solution to overcoming the negative consequences of water deficits in crop production which has been proposed as an adaptive mechanism for drought and salt tolerance. Indeed, osmolyte accumulation (OA) in plant cell results in a decrease of the cell osmotic potential and help in the maintenance of water absorption and cell turgor pressure, which might contribute to sustaining physiological processes, such as stomatal opening, photosynthesis and expansion growth (Kaouther et al., 2012).

\section{Malondialdehyde (MDA) content}

The effect of salt stress on melondialdehyde (MDA) content was statistically significant (Figure 6). At $60 \mathrm{mM}$ saline condition relative (per cent of control) MDA content of the genotypes ranged from $106 \%$ to $116 \%$. Highest relative MDA content was obtained from genotype BD-881 (116\%) followed by BD-897 (114\%), and BARI Kaon-1 (112\%) and it was lowest in BD-878 (106\%). At $120 \mathrm{mM}$ saline condition relative (per cent of control) MDA content of the genotypes ranged from $107 \%$ to $119 \%$. Highest relative MDA content was obtained from genotype BD-881 (119\%), followed by BARI-Kaon-1 (116\%), and BD-897 $(110 \%)$ and it was lowest in BD-878 $(106 \%)$. The relative MDA content was significantly higher in saline condition than control in all the genotypes. The rise in MDA content under stress conditions suggests that water/saline stress could induce membrane lipid peroxidation by means of ROS (Sairam et al., 2002). It is also generally accepted that the accumulation of MDA, a measure of lipid peroxidation, is considered a potential marker of oxidative damage (Jouve et al., 2003; Ashraf, 2009; Ashraf et al., 2010). Generally, MDA concentration changes with increasing salt concentration e.g. in Limonium bicolor, it decreased at $100 \mathrm{~mm}$, while increased at $200 \mathrm{~mm} \mathrm{NaCl}$ indicating that $\mathrm{L}$. bicolor plants were better protected from oxidative damage under saline regime $(\mathrm{Li}, 2008)$. In the present investigation, the lower relative values of MDA in BD-878 indicate that at cellular level this genotype is better equipped with efficient free radical quenching system that offers protection against oxidative stress. 


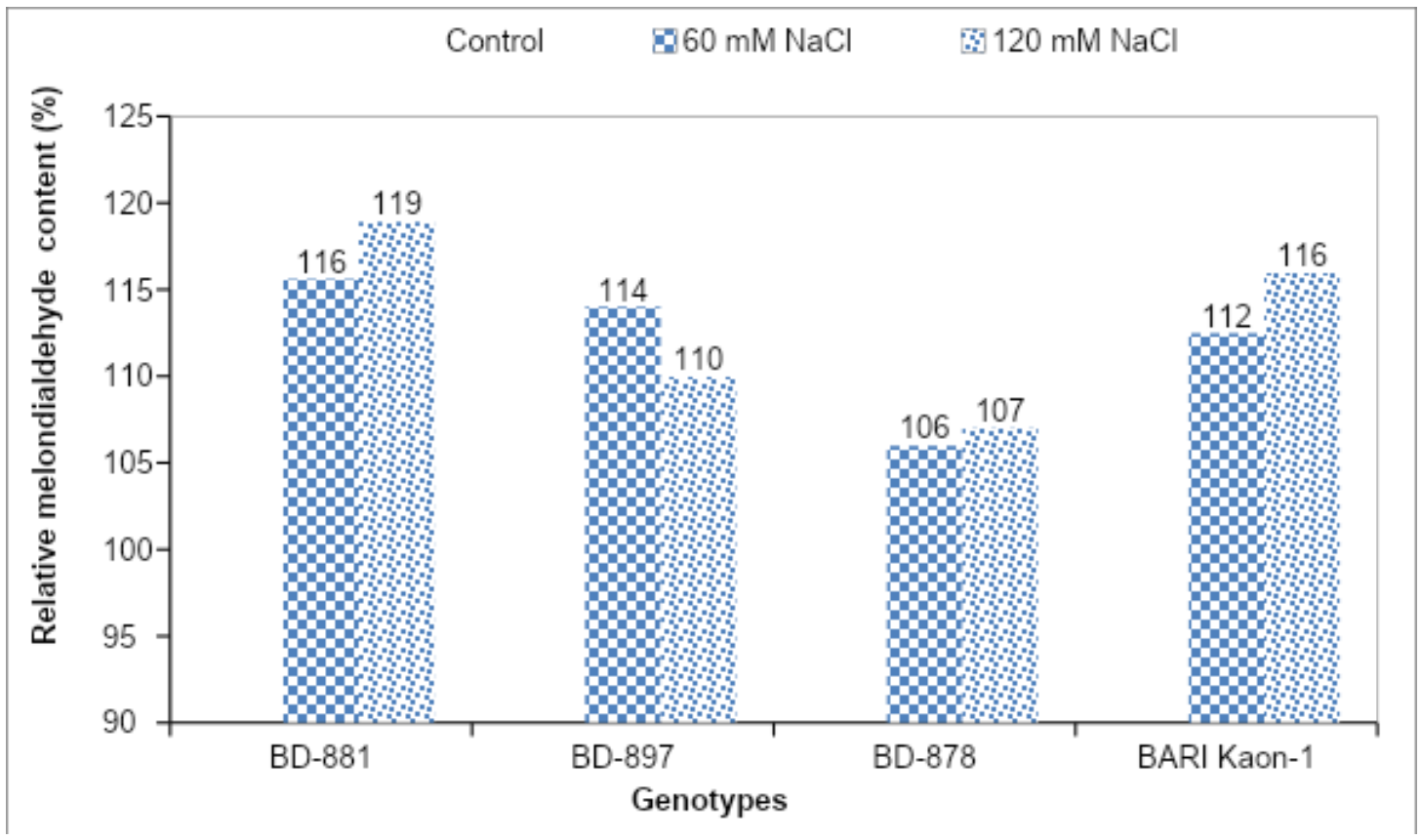

Fig. 6. Relative melondialdehyde content of four Foxtail millet genotypes as affected by salinity.

\section{Effect of salt stress on yield and yield contributing characters}

\section{Number of tiller}

The effect of salt stress on number of tiller/plant was statistically significant (Table 3 ). At control condition, the tiller number was the highest in BD-878 (12.33), followed by BD-881 (9.33), BD-897 (9.00), while the lowest was in BARI Kaon-1 (8.67). At $60 \mathrm{mM}$ saline condition the highest tiller number was recorded with BD-878 (10.33) and the lowest was in BBARI Kaon-1 (7.00). Relative (per cent of control) tiller number of the genotypes ranged from $78.57 \%$ to $83.78 \%$. Highest relative tiller number was obtained from genotype BD-878 $(83.78 \%)$, followed by BD-897 (81.48\%), and BARI Kaon-1 $(80.77 \%)$ and it was lowest in BD-881 $(78.57 \%)$. At $120 \mathrm{mM}$ saline condition the highest tiller number was recorded with BD-878 (7.00) and the lowest was in BD-881 (4.48). Relative (per cent of control) tiller number of the genotypes ranged from $48.01 \%$ to $67.74 \%$. Highest relative tiller number was obtained from genotype BD-878 (67.74\%), followed by BARI-Kaon-1 (57.69\%) and BD-897 $(55.56 \%)$ and it was lowest in BD-881 (48.01\%). Tiller number reduction due to salinity was lower in BD-881 (32.26\%) while that was higher in BD-878 (51.99\%).

Table 3. Tiller number and panicle number of foxtail millet genotypes as affected by salinity

\begin{tabular}{ccccccc}
\hline Genotypes & \multicolumn{3}{c}{ Tiller number plant $^{-1}$} & \multicolumn{3}{c}{ Panicle number-plant $^{-1}$} \\
\cline { 2 - 7 } & Control & $\begin{array}{c}60 \mathrm{mM} \\
\text { salinity }\end{array}$ & $\begin{array}{c}120 \mathrm{mM} \\
\text { salinity }\end{array}$ & Control & $60 \mathrm{mM}$ & $120 \mathrm{mM}$ \\
& & & & salinity & salinity \\
\hline BD-881 & 9.33 & 7.33 & 4.48 & 9.33 & 7.33 & 5.00 \\
& & $(78.57)$ & $(48.01)$ & & $(78.57)$ & $(53.57)$
\end{tabular}




\begin{tabular}{lcccccc} 
BD- 897 & 9.00 & 7.33 & 5.00 & 8.67 & 6.33 & 5.00 \\
& & $(81.48)$ & $(55.56)$ & & $(73.08)$ & $(57.69)$ \\
BD- 878 & 12.33 & 10.33 & 7.00 & 8.00 & 7.00 & 6.00 \\
& & $(83.78)$ & $(67.74)$ & & $(87.50)$ & $(85.71)$ \\
BARI kaon-1 & 8.67 & 7.00 & 5.00 & 5.67 & 4.33 & 3.67 \\
& & $(80.74)$ & $(57.69)$ & & $(76.47)$ & $(64.71)$ \\
\hline LSD $_{(0.05)}$ & 2.61 & & & 2.13 & \\
\hline CV (\%) & \multicolumn{7}{c}{20.0} &
\end{tabular}

Values in parenthesis indicates percent of control

\section{Number of panicle}

The effect of salt stress on number of panicle/plant was statistically significant (Table 3). At control condition, the panicle number was the highest in BD-881 (9.33), followed by BD-897 (8.67), BD-878 (8.00), while the lowest was in BARI Kaon-1 (5.67). At $60 \mathrm{mM}$ saline condition the highest panicle number was recorded with BD-878 (7.33) and the lowest was in BBARI Kaon-1 (4.33). Relative (per cent of control) panicle number of the genotypes ranged from $73.08 \%$ to $87.50 \%$. Highest relative panicle number was obtained from genotype BD-878 $(87.50 \%)$, followed by BD-881 (78.57\%) and BARI Kaon-1 (76.47), and the lowest was in $\mathrm{BD}-897(73.08)$. At $120 \mathrm{mM}$ saline condition the highest panicle number was recorded with BD-878 (6.00) and the lowest was in BARI-Kaon-1 (3.67). Relative (per cent of control) panicle number of the genotypes ranged from $53.57 \%$ to $85.71 \%$. Highest relative panicle number was obtained from genotype BD-878 (85.71\%), followed by BARI-Kaon-1 (64.71\%) and BD-897 (57.69\%) and it was lowest in BD-881 (53.57\%). Panicle number reduction due to salinity was lower in BD-881 (14.29\%) while that was higher in BD-878 (46.43\%).

\section{Panicle weight}

The effect of salt stress on panicle weight (g/plant) was statistically significant (Table 4). At control condition, the panicle weight was the highest in BARI Kaon-1 (8.00), followed by BD-878 (4.94), BD-897 (7.46), and the lowest was in BD-881 (4.44). At $60 \mathrm{mM}$ saline condition the highest panicle weight was recorded with BARI Kaon-1 (5.59) and the lowest was in BD-881 (3.12). Relative (per cent of control) panicle weight of the genotypes ranged from $42.78 \%$ to $85.48 \%$. Highest relative panicle weight was obtained from genotype BD-878 $(85.48 \%)$, followed by BD-881 $(70.26 \%)$, and BARI-Kaon-1. $(69.86 \%)$ and it was lowest in BD-897 (42.78\%). At $120 \mathrm{mM}$ saline condition the highest panicle weight was recorded with BARI-Kaon-1 (2.34) and the lowest was in BD-881 (1.92). Relative (per cent of control) panicle weight of the genotypes ranged from $27.71 \%$ to $54.05 \%$. Highest relative panicle weight was obtained from genotype BD-878 (54.05\%), followed by BD-881 (43.29\%) and BARI-Kaon-1(29.25) and it was lowest in BD-897 (27.71\%). Panicle weight reduction due to salinity was lower in BD-878 (45.95\%) while that was higher in BD-897 (72.29\%).

\section{Seed yield}

The effect of salt stress on seed yield (g/plant) was statistically significant (Table 4). At control condition, the seed yield was the highest in BD-897 (11.71), followed by BD-878 (9.51), BARI kaon-1 (9.19), and the lowest was in BD-881 (9.10). At $60 \mathrm{mM}$ saline condition the highest seed yield was recorded with BD-878 (7.60) and the lowest was in BD-897 (3.83). Relative (per cent of control) seed yield of the genotypes ranged from $32.68 \%$ to $79.86 \%$. Highest relative seed yield was obtained from genotype BD-878 $(79.86 \%)$, followed by BARI kaon-1 
(67.30\%) and BD-881 (59.08\%) and it was lowest in BD-897 (32.68\%). At $120 \mathrm{mM}$ saline condition the highest seed yield was recorded with BD-897 (3.30) and the lowest was in BD-881 (1.01). Relative (per cent of control) seed yield of the genotypes ranged from $11.13 \%$ to $28.21 \%$. Highest relative seed yield was obtained from genotype BD-897 $(28.21 \%)$, followed by BD-878 (20.45\%) and BARI-Kaon-1 (12.77\%) and it was lowest in BD-881 $(11.13 \%)$. Seed yield reduction due to salinity was lower in BD- 897 (71.79\%), while that was higher in BD-881 (88.87\%). Salinity induced yield reduction has been reported in many crop species, which depends upon the severity and duration of the stress period. Salinity was also found to reduce the shoot length, number and size of spikes and the grain yield (Hendawy et al., 2012).

Table 4. Panicle weight and seed yield of Foxtail millet genotypes as affected by salinity

\begin{tabular}{|c|c|c|c|c|c|c|}
\hline \multirow[t]{2}{*}{ Genotypes } & \multicolumn{3}{|c|}{${\text { Panicle weight }\left(\text { g plant }^{-1}\right)}$} & \multicolumn{3}{|c|}{ Seed yield $\left(\right.$ g plant $\left.^{-1}\right)$} \\
\hline & Control & $\begin{array}{l}60 \mathrm{mM} \\
\text { salinity }\end{array}$ & $\begin{array}{l}120 \mathrm{mM} \\
\text { salinity }\end{array}$ & Control & $\begin{array}{l}60 \mathrm{mM} \\
\text { salinity }\end{array}$ & $\begin{array}{l}120 \mathrm{mM} \\
\text { salinity }\end{array}$ \\
\hline \multirow[t]{2}{*}{ BD- 881} & 4.44 & 3.12 & 1.92 & 9.10 & 5.37 & 1.01 \\
\hline & & (70.26) & (43.29) & & (59.08) & (11.13) \\
\hline \multirow[t]{2}{*}{ BD- 897} & 7.46 & 3.19 & 2.07 & 11.71 & 3.83 & 3.30 \\
\hline & & $(42.78)$ & (27.71) & & (32.68) & $(28.21)$ \\
\hline \multirow[t]{2}{*}{ BD- 878} & 4.94 & 4.22 & 2.28 & 9.51 & 7.60 & 1.55 \\
\hline & & (85.48) & $(54.05)$ & & (79.86) & (20.45) \\
\hline \multirow{2}{*}{$\begin{array}{l}\text { BARI } \\
\text { kaon-1 }\end{array}$} & 8.00 & 5.59 & 2.34 & 9.19 & 6.19 & 1.17 \\
\hline & & $(69.86)$ & $(29.25)$ & & $(67.30)$ & $(12.77)$ \\
\hline $\operatorname{LSD}_{(0.05)}$ & & 2.18 & & & 4.00 & \\
\hline CV (\%) & & 11.4 & & & 10.1 & \\
\hline
\end{tabular}

Values in parenthesis indicates percent of control

Saline water irrigations with salinity increasing from 1 to $16 \mathrm{dS} \mathrm{m}^{-1}$ had been noticed to linearly decrease seed and straw yield, harvest index and 1000 grain weights in foxtail millet and the harvested seeds from these treatments were found to germinate into normal seedlings (Thimmaiah et al., 1989). In the present study, the reduction in seed yield under salt stress was associated with dramatic decrease in all these yield components.

\section{Conclusion}

Based on the above results it may be concluded that BD-878 showed relatively higher salinity tolerance in respect of dry matter accumulation and yield compared to other genotypes studied. Higher salinity tolerance in BD-878 was associated with better water relations and osmotic adjustment with accumulation of higher amount of proline. Furthermore, under salinity conditions less damaged chlorophylls as well as lower accumulation of melondialdehyde content contributed to the higher salinity tolerance in BD-878 compared to other genotypes.

\section{Acknowledgement}

The authors are grateful to Ministry of Science and Technology, Government of Bangladesh for funding the research. 


\section{References}

Abass, S.M. and H.I. Mohamed. 2011. Alleviation of adverse effects of drought stress on common bean (Phaseolus vulgaris L.) by exogenous application of hydrogen peroxide. Bangladesh J. Bot. 41: 75-8

Abdelhamid, M.T., M.S.H. Sadak, U.R.S. Schmidhalte and A.K.M. El-Saady. 2013. Interactive Effects of Salinity Stress and Nicotinamide on Physiological and Biochemical Parameters of Faba Bean Plant. Acta boil. Colom. 18: 3-14.

Abraham, E., G. Rigo, G. Szekely, R. Nagy, C. Koncz and L. Szabados. 2003. Light dependent induction of proline biosynthesis by abscisic acid and salt stress is inhibited by brassinosteroid in Arabidopsis. Plant Molecul. Biol. 51: 363-372.

Amirjani, M.R. 2010. Effects of salinity stress on growth, mineral composition, proline content, antioxidant enzymes of soybean. American J. Physiol. 5: 350-360

Ashraf, M. 2009. Biotechnological approach of improving plant salt tolerance using antioxidants as markers. Biotech- nol. Adv. 27: 84-93.

Ashraf, M., N.A. Akram, R.N. Arteca and M.R. Foolad, 2010. The physiological, biochemical and molecular roles of brassinosteroids and salicylic acid in plant processes and salt tolerance. Crit. Rev. Plant Sci. 29: 162-190.

Arora, A., R.K. Sairam and G.C. Srivastava. 2002. Oxidative stress and antioxidative systems in plants. Curr. Sci. 82: 1227-1238.

Banon, S., J. Ochoa, J.A. Franco, J.J. Alarcon and M.J. Sanchez-Blanco. 2006. Hardening of oleander seedlings by deficit irrigation and low air humidity. Environ. Expt. Bot. 56: 36-43.

Bates, L., R.P. Waldren and I.D. Teare. 1973. Rapid determination of free proline for water-stress studies. Plant Soil. 39: 205-207.

Doust, A.N., E.A. Kellogg, K.M. Devos and J.L. Bennetzen. 2009. Foxtail millet: a sequence-driven grass model system. Plant Physiol. 149: 137-141.

Escuredo, I.P., C. Arrese-Igor and M. Becana. 1998. Oxidative damage in pea plants exposed to water deficit or paraquat. Plant Physiol 116: 173-181.

Farooq, M., A. Wahid, N. Kobayashi, D. Fujita and S.M.A. Basra. 2009. Plant drought stress: effects, mechanisms and management. Agron. Sustain. Dev., 29: 185-212.

Garsia-Sanchez, F., J.L. Jufon, M. Carvaial and J.P. Syverstem. 2002. Gas exchange, chlorophyll and nutrient contents in relation to $\mathrm{Na}+$ and $\mathrm{Cl}-$ accumulation in 'Sunburst' mandarin grafted on different rootstocks. Plant Sci. 162: 705-712.

Gomez, A. A. and A.A. Gomez. 1984. Statistical procedure of Agricultural Research. Second Edition. John Wiley and Sons. New York.

Health, R.L. and L. Packer. 1968. Photoperoxidation in isolated chloroplasts. I. Kinetics and stoichiometry of fatty acid peroxidation. Archives Biochem. Biophy. 125: 189-198.

Hendawy, S.F., S.E. El-Sherbeny, M.S. Hussein and A.A. Youssef. 2002. Evaluation of some cultivars of foxtail plants under salinity conditions. J. Appl. Sci. Res. 8: 620-627.

Jakoby, M.J., C. Weinl, S. Pusch, S.J. Kuijt, T. Merkle, N. Dissmeyer and A. Schnittger. 2006. Analysis of the subcellular localization, function, and proteolytic control of the Arabidopsis cyclin-dependent kinase inhibitor ICK1/KRP1. Plant Physiol. 141(4): 1293-1305.

Jouve, L., L. Hoffmann and J.F. Hausman. 2003. Polyamine, carbohydrate, and proline content changes during salt stress exposure of aspen (Populus tremula L): involvement of oxidation and osmoregulation metabolism. Plant Biol. 6: 74-80. 
Kafi, M., G.H. Zamani and S.G.H. Ghoraishi. 2009. Relative salt tolerance of south Khorasan millets. DESERT. 14: 63-70.

Kaouther, Z., F.M, Ben, F. Mani and C. Hannachi. 2012. Impact of salt stress ( $\mathrm{NaCl})$ on growth, chlorophyll content and fluorescence of Tunisian cultivars of chili pepper (Capsicum frutescens L.). J. Stress Physiol. Biochem.. 8: 236-252.

Khattab, H. 2007. Role of glutathione and polyadenylic acid on the oxidative defense systems of two different cultivars of canola seedlings grown under saline conditions. Australian J. Basic Appli. Sci. 1: 323-334.

Lacerda, C.F.D., J. Cambraia, M.A. Oliva and H.A. Ruiz. 2003. Osmotic adjustment in roots and leaves of two sorghum genotypes under $\mathrm{NaCl}$ stress. Brazilian J. Plant Physiol. 15(2): 113-118.

Lavisolo, C. and A. Schuber. 1998. Effects of water stress on vessel size xylem hydraulic conductivity in Vitis vinifera L. J. Expt. Bot. 49: 693-700.

$\mathrm{Li}, \mathrm{Y} .2008$. Kinetics of the antioxidant response to salinity in the halophyte Limonium bicolour. Plant Soil Environ. 54: 493-497.

Maas, E.V. 1985. Crop tolerance to saline sprinkling water. Plant Soil. 89: 273-284.

Muthulakshmi, S.M., G.S. Gurulakshmi and S. Rajathi. 2013. Effect of Salt Stress on Physiological and Biochemical Characteristics in Solanum nigrum L. Int. J. Sci. Res. 4: 12-20.

Sadak, M.S.H. and M.G. Dawood. 2014. Role of ascorbic acid and $\alpha$ tocopherol in alleviating salinity stress on flax plant (Linumusi tatissimum L.). J. Stress Physiol. Biochem. 10: 93-111.

Sairam, R.K., K.V. Rao and G.C. Srivastava. 2002. Differential response of wheat genotypes to long term salinity stress in relation to oxidative stress, antioxidant activity and osmolyte concentration. Plant Sci. 163: 1037- 1046.

Taie, H., M.T. Abdelhamid, M.G. Dawood and R.M. Nassar. 2013. Pre-sowing seed treatment with proline improves some physiological, biochemical and anatomical attributes of faba bean plants under sea water stress. J. Appl. Sci. Res. 9: 2853-2867.

Terzi, R., A. Sağlam, N. Kutlu, H. Nar and A. Kadıoğlu. 2010. Impact of soil drought stress on photochemical efficiency of photosystem II and antioxidant enzyme activities of Phaseolus vulgaris cultivars. Turk. J. Bot. 34: 1-10.

Tewari, T. N. and B.B. Singh. 1991. Stress studies in lentil (Lens esculenta Moench). Plant Soil. 136(2): 225-230.

Thimmaiah, S.K., D.P. Viswanath, B.S. Vyakarnahal and C.S. Hunshal. 1989. Effect of salinity on yield, seed quality and biochemical characteristics in Setaria italica L. Cereal Chem. 66: 525-527.

Verslues, P.E., M. Agarwal, S. Katiyar-Agarwal, J. Zhu and K. Zhu. 2006. Methods and concepts in quantifying resistance to drought, salt and freezing, abiotic stresses that affect plant water status. The Plant J. 45(4): 523-539.

Velu, G. and K. Palanisami. 2001. Impact of moisture stress and ameliorants on growth and yield of sunflower. Madras Agric. J. 88(10/12): 660-665.

Vetriventhan, M., H.D. Upadhyaya, C.R. Anandakumar, S. Senthilvel, H.K. Parzies. A. Bharathi, R.K. Varshney and C.L.L. Gowda. 2012. Assessing genetic diversity, allelic richness and genetic relationship among races in ICRISAT foxtail millet core collection. Plant Gen. Res. 10: 214-223.

Wang, J. 2005. Carbon-nanotube based electrochemical biosensors: A review. Electro analysis: An Int. J. Dev. Fund. Prac. Aspects Electro Analysis. 17(1): 7-14. 
Witham, F.H., D.F. Blaydes and R.M. Devlin. 1986. Chlorophyll absorption spectrum and quantitative determinations. In. Exercise in Plant Physiology. Second edition. Boston, pp. 128-131.

Zhu, J.K. 2004. Plant salt tolerance. Trends Plant Sci. 6(2): 66-71. 